\title{
TREATABILITY STUDY FOR RIVER WATER WITH MORINGA OLEIFERA AND NIRMALI SEEDS
}

\author{
V.T.Gaikwad ${ }^{1}$, G.R.Munavalli ${ }^{2}$ \\ ${ }^{1}$ Associate Professor, P.V.P.I.T,Budhgaon, Sangli \\ ${ }^{2}$ Associate Professor, Department of Civil Engineering, Walchand college of Engineering, Sangli
}

\begin{abstract}
The laboratory study was carried out to study the effectiveness of Moringa Oleifera and Nirmali seeds for turbidity and hardness removal of Krishna river water at Sangli, Maharashtra. The Moringa Oleifera and Nirmali seed extract was used with varying dosage of $10 \mathrm{mg} / \mathrm{L}$ to $100 \mathrm{mg} / \mathrm{L}$, and residual turbidity and hardness was measured. Simultaneously change in pH, Alkalinity, $T D S$, and COD was observed. Both the natural coagulants were found effective for turbidity removal. Turbidity removal of 67 to $87 \%$ with Moringa oleifera and 30 to $91 \%$ with Nirmali seeds at the optimum dose of $50 \mathrm{mg} / \mathrm{L}$ was observed.
\end{abstract}

For hardness removal Moringa Oleifera is more effective ( 7.7 to $47 \%$ removal) with optimum dose of $40 \mathrm{mg} / \mathrm{L}$, as compared to Nirmali seeds (9.8 to $28.6 \%$ removal).

For both the coagulants no significant variation was observed in the $\mathrm{pH}$ and Alkalinity of water sample.TDS reduction is directly proportional to the reduction in hardness and organic matter of the water sample increases with the added dose of coagulants.

\section{INTRODUCTION}

The use of water is increasing rapidly with our growing population. The surface and ground water vary greatly in quantity and quality from season to season. Since most of the Indian rivers are non-perennial with meagre storages, and generally located at far off distances from the rural villages, it has generally not been feasible to supply surface water to the scattered and isolated rural areas except in few cases. The pollution and contamination of surface and ground water source has greatly impaired the quality of available water. The major impurities in surface water are turbidity, pathogens, and dissolved solids.

More than $80 \%$ of the Indian population live in rural areas, but only about $60 \%$ of them have access to some form of potable water supply, with only about $20 \%$ having piped water supply, $\left(\mathrm{Garg}^{3}\right)$. It has not been feasible to cover all the villages with potable water supplies because of various constraints, such as scattered and inaccessible nature of village, non availability of nearby water sources, nonavailability of adequate funds to take up those projects which may serve only a few people, and non-availability of power for the required period, and hence may not become financially viable. In view of these constraints, it becomes very difficult to supply potable water to the villages through a full fledged conventional water treatment plant, and hence special methods should be devised and adopted to treat the available water supplies in rural area.

Bhole and Shrivastava ${ }^{2}$ used six natural materials as Nirmali seed, Masur, Jawar, Potato, Singhara and Drum stick as a coagulant and coagulant aid. Muyibi and Evison ${ }^{4}$ carried out the optimization studies on physical factors including rapid mix velocity gradient and time, slow mix velocity gradient and time, and dosage of Moringa oleifera for low, medium and high raw water turbidities (50-750 NTU). There was optimum dosage at 50 and $100 \mathrm{mg} / \mathrm{l}$ respectively for initial turbidity of 50-150 NTU and 250-550 NTU. The residual turbidity recorded was less than 10 NTU in all cases. Okuda et al. $^{6}$ studied coagulation mechanism of salt solutionextracted active component in Moringa oleifera seeds. Raghuwanshi et al. ${ }^{7}$ (2002) used agro-based materials to determine efficacy in water treatment. The agro-based materials evaluated are Surjana seed (Moringa oleifera), Nirmali seed (Strychnos potatorum), and maize (Zeemays). Sarpong and Richerdson ${ }^{9}$ studied the use of Moringa oleifera seed extract as a primary coagulant for a local river water source with respect to turbidity removal and total coliform reduction.

$\mathrm{Sani}^{8}$ carried out jar tests with Moringa oleifera as coagulant using water from four different sources (viz two surface and two shallow wells) with turbidity from 100 to 800 NTU and 80 to 150 NTU respectively and hardness from 180 to 300 $\mathrm{mg} / \mathrm{L}$ as $\mathrm{CaCO}_{3}$. It was observed that in addition to turbidity reduction of $92-99 \%$, the hardness was also reduced by $60-$ $70 \%$ after coagulation two hours settling. The softening property of Moringa oleifera was accidently discovered in their study. Muyibi and Evison ${ }^{5}$ investigated the possible use of Moringa oleifera seed suspension for the softening of hard water. $\operatorname{Varekar}^{9}$ (2009) carried out softening study using different types of seed extracts. The author observed that Moringa oleifera extract gives better performance as compared to that of Maize and Okra seeds. The ammonia treated seeds were more effective, but cause significant increase in $\mathrm{pH}$. The conductivity and alkalinity of softened water shown same trend as that of $\mathrm{pH}$. The COD of softened water increased significantly for all seed materials. 
It was also observed that softening potential of Moringa oleifera seeds vary depending on the quality of seeds.

This literature study shows that Moringa oleifera and Nirmali seeds are effective for turbidity removal, but for the selection between these coagulants a comparative study is to be carried out under similar experimental and environmental conditions. The potential of Nirmali seeds for water softening needs to be explored, which was not carried out in the previous studies. .

The objectives of present study are to carry out coagulation studies using Moringa oleifera and Nirmali seeds for treating water with turbidity level ranging from 5 to 50 NTU, to assess the potential of these coagulants for softening surface water and to assess the quality of water after coagulation and softening with these coagulants. The suitability and effectiveness of these two coagulants is evaluated based on this study.

\section{EXPERIMENTAL DESIGN}

\subsection{Materials}

a) Natural Coagulants-Naturally dried Moringa oleifera seeds obtained from the drumstick trees in nearby areas of Sangli city and Nirmali (Strychnos potatorum) seeds available in the market were used for the study.

b) Water sample-Turbid Water from Krishna river, Sangli was collected at a location behind the Ganesh temple between 7.00 am to 8.00 am during the rainy season in the month of July 2014 and stored in the laboratory in the airtight plastic containers in dark room. This sample was used during the same year for the present study.
$100 \mathrm{ml}$ sample water and blended in high speed mixer for 30 $\mathrm{sec}$ to extract active ingredients. Suspension is filtered through a cloth and stock solution is prepared $(10,000$ $\mathrm{mg} / \mathrm{L}$ ). The solution is prepared fresh for use ${ }^{3}$.

\subsubsection{Jar Test}

The jar test was conducted with 5 beakers, each containing 1 liter water sample. The coagulant dose of 10,20,30,40, and $50 \mathrm{mg} / \mathrm{l}$ was used. Rapid mixing is carried out for 60 seconds with a speed of 100-200 rpm. Then slow mixing is carried out for 30 minutes with a speed of $20-40 \mathrm{rpm}$. The sample is allowed to settle for 30 minutes and content of water sample $1 \mathrm{~cm}$ below the water surface was collected and subjected to analysis. The procedure is repeated by using 60,70,80,90, and $100 \mathrm{mg} / \mathrm{L}$ coagulant dose.

\subsection{Analysis of Water Sample}

Analysis of water samples was carried out by using standard methods for the Examination of Water and Waste Water by APHA(2005). The water sample is analyzed for $\mathrm{p}^{\mathrm{H}}$ using electrometric method, Alkalinity and Total Hardness is determined by titrati method, Turbidity is determined by Nephelometer, TDS is determined by using digital electrode and Organic Matter is determined by COD test.

\section{RESULTS AND DISCUSSION}

The river water having turbidity 5 to 50 NTU, hardness 120 to $140 \mathrm{mg} / \mathrm{L}$ as $\mathrm{CaCO}_{3}, \mathrm{p}^{\mathrm{H}} 7$ to 8 , TDS 300 to $400 \mathrm{mg} / \mathrm{L}$ and alkalinity $200 \mathrm{mg} / \mathrm{L}$ as $\mathrm{CaCO}_{3}$ is used for the study. The study was carried out using freshly prepared seed extract and the results are confirmed by taking three trials.

\subsection{Methods}

\subsubsection{Preparation of Extract from Seeds}

Seeds ground to fine powder using domestic grinder and powder is sieved through fine sieve. $1 \mathrm{gm}$ powder is put in

\subsection{Turbidity}

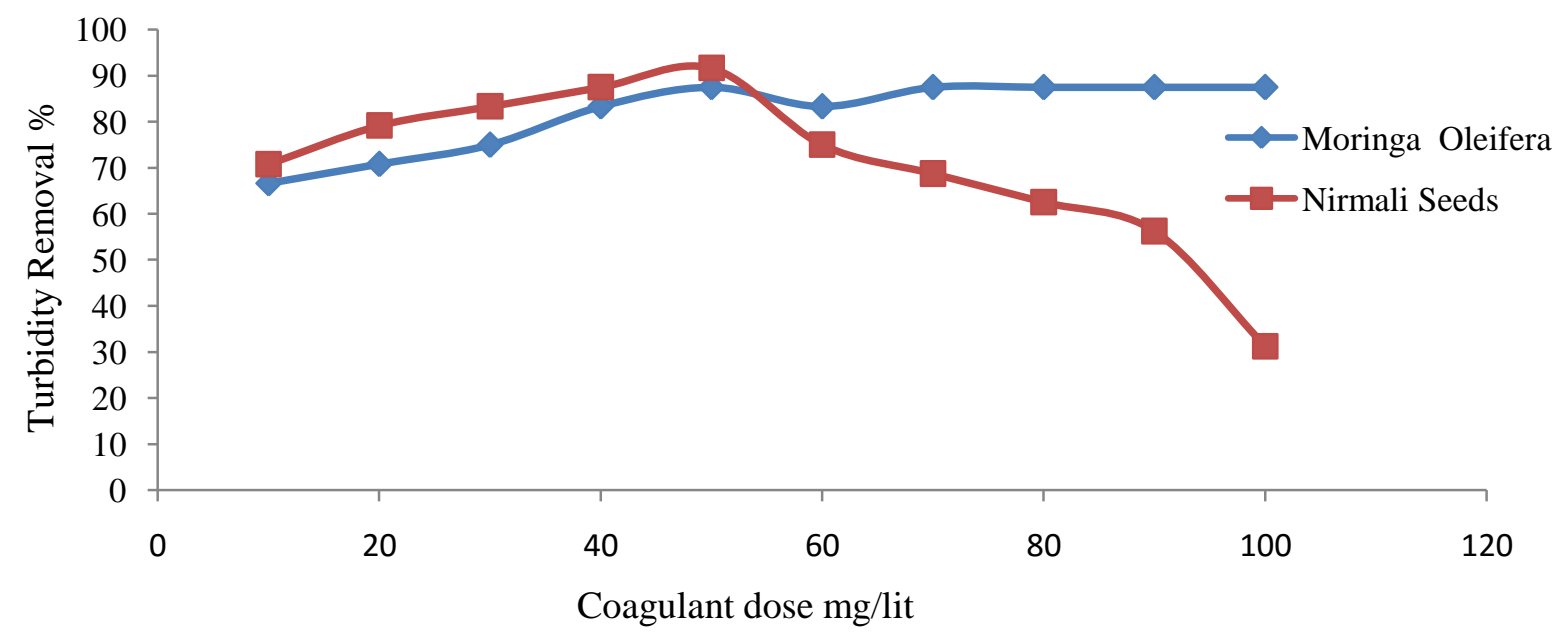

Fig. 1 Effect of dose of seed extract on Turbidity Removal 
Turbidity removal by natural coagulants is by adsorption and chemical bridging.Fig 1 shows that turbidity removal increases with added dose of Moringa Oleifera, maximum removal was observed at $50 \mathrm{mg}$./lit and afterwards residual turbidity remains constant at $3 \mathrm{NTU}$, which indicates that further increase in coagulant dose is not effective in the formation of flocs of finely divided colloidal particles because of re-stabilization of the particles. The turbidity removal increases with added dose of Nirmali seed extract up to $50 \mathrm{mg} / \mathrm{l}$ dose and then there is gradual increase in the residual turbidity due to insufficient number of particles to form bridge with coagulant. The floc formed with both coagulants is light in weight and suggests the need of some agent to make it heavy.

\subsection{Hardness}

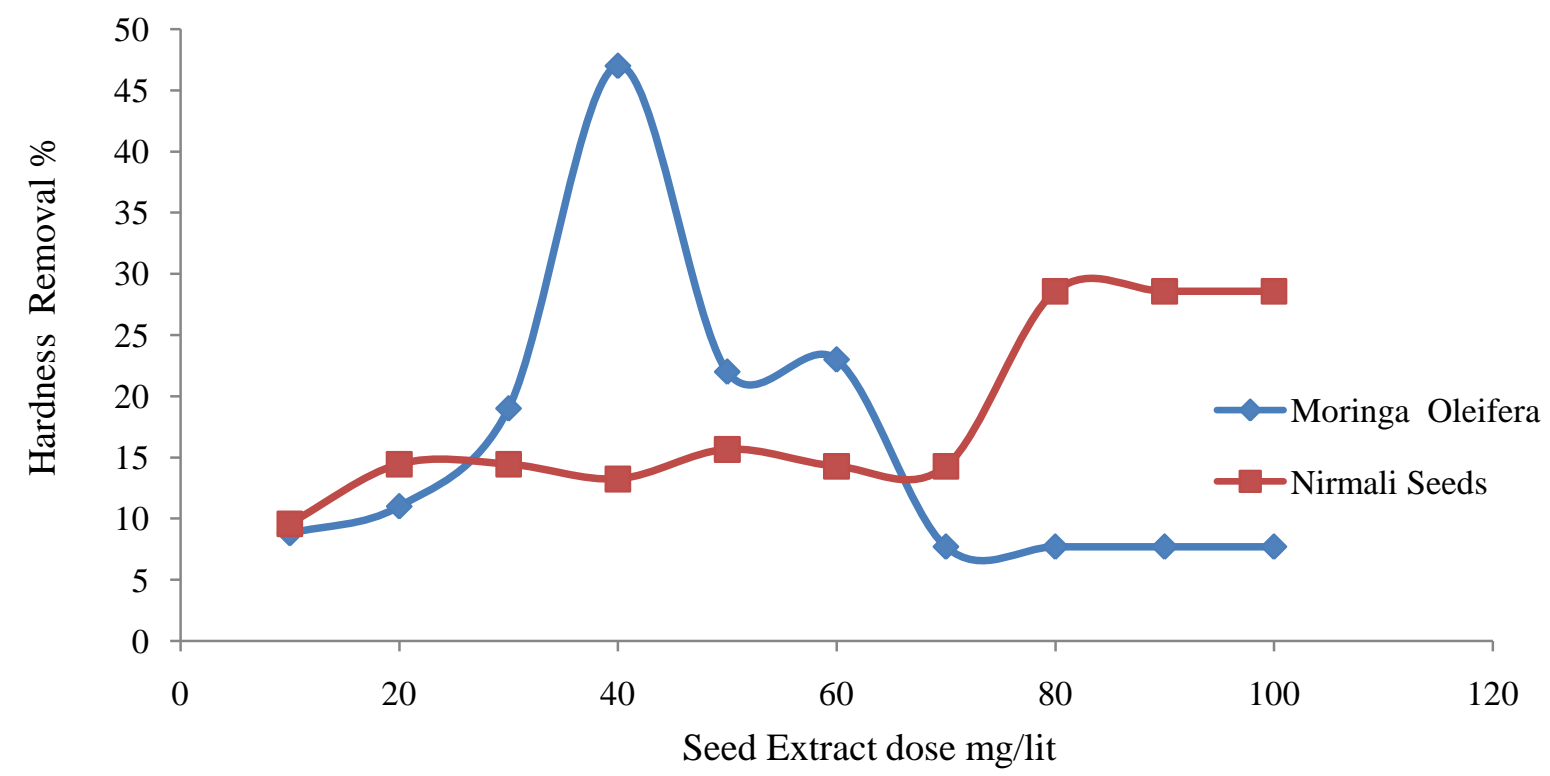

Fig. 2 Effect of dose of seed extract on Hardness Removal

Fig.2 shows that Hardness removal increases with dose of Moringa Oleifera from 10 to $40 \mathrm{mg} / \mathrm{l}$ and then reduces to 7.7 $\%$ and afterwards remains constant. For hardness removal with Nirmali seed extract maximum $28 \%$ efficiency is observed at a dose of $80 \mathrm{mg} / \mathrm{l}$, after which it remains constant with added dose of Nirmali seed extract From this study it can be interpreted that both the seed extract react with hardness causing insoluble ions to form insoluble compounds. The Moringa Oleifera seed extract is having more charged sites as compared with Nirmali seed extract for adsorption and chemical bridging.fig.4 shows the residual hardness at different doses of coagulants.

\section{$3.3 \mathrm{pH}$ and Alkalinity}

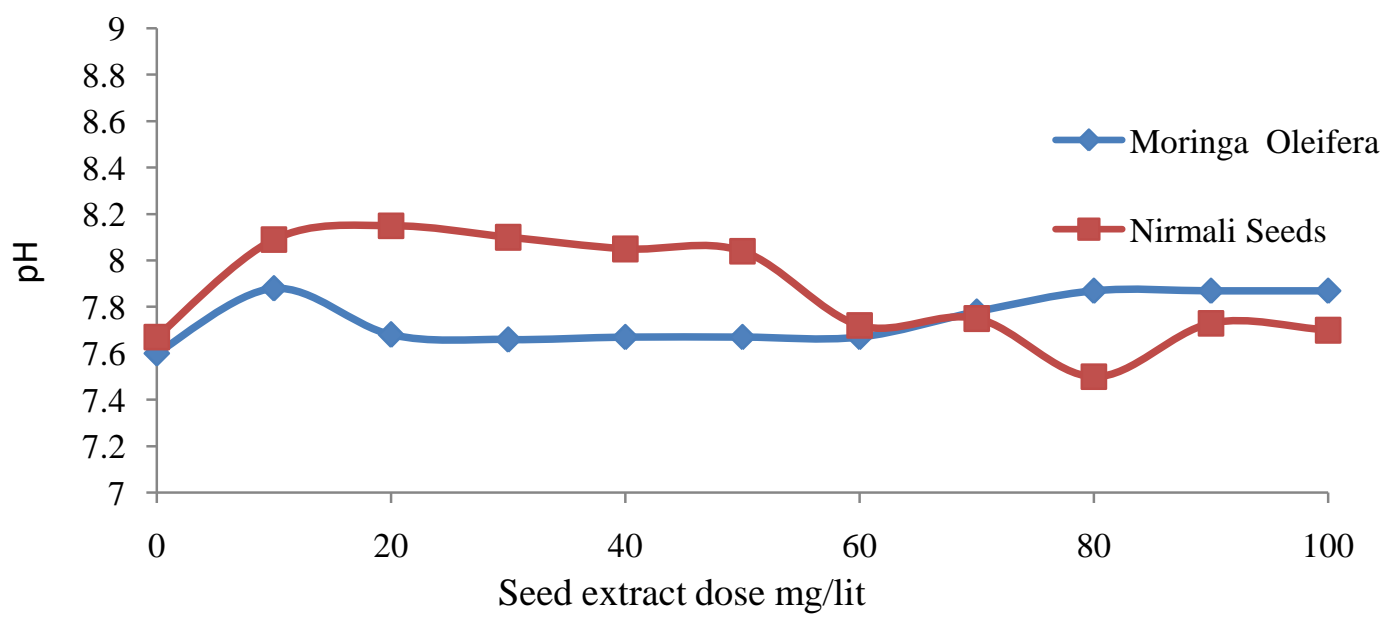

Fig. 3 Variation in $\mathrm{pH}$ of water sample with dose of seed extract 


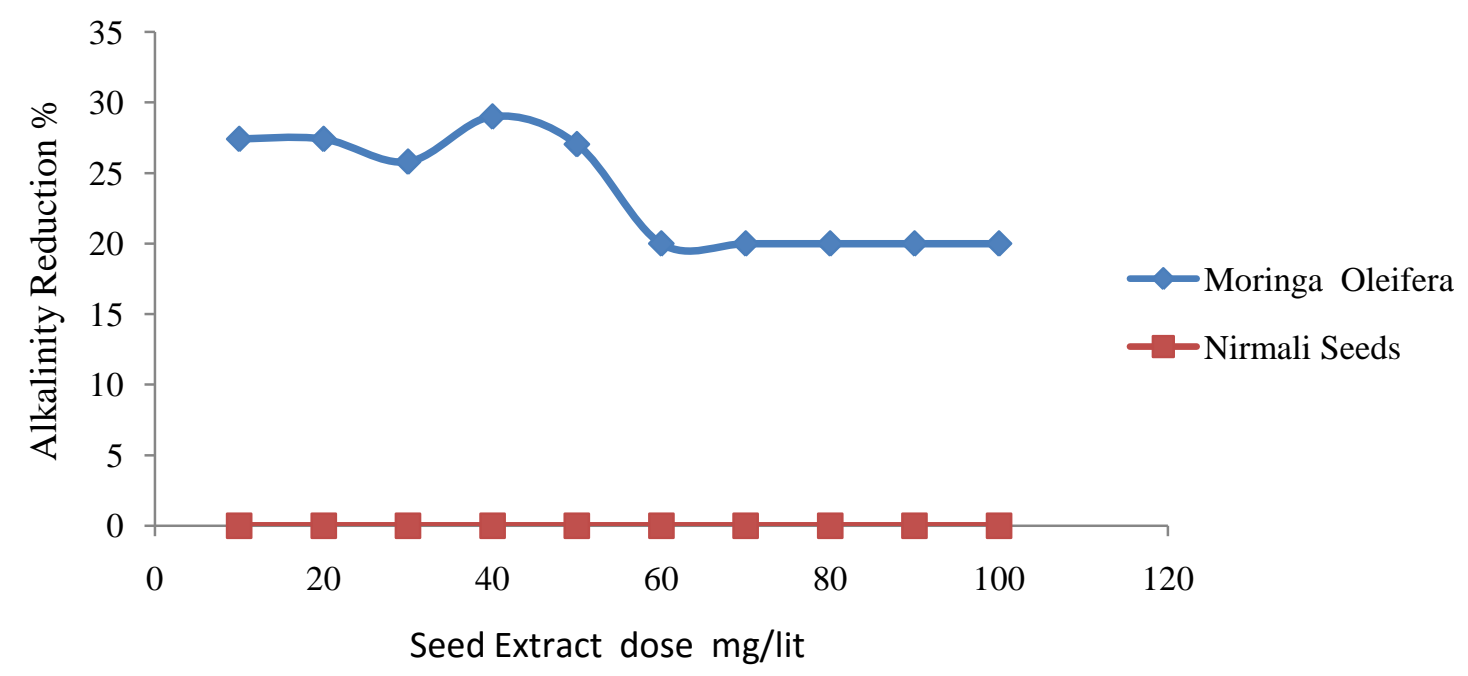

Fig.4 Variation in Alkalinity of water sample with dose of seed extract

Fig. 3 and 4 shows that no significant variation was observed in the $\mathrm{pH}$ and Alkalinity of water sample for both the coagulants, which indicates that these coagulants are having natural buffering capacity.

\subsection{TDS and COD}

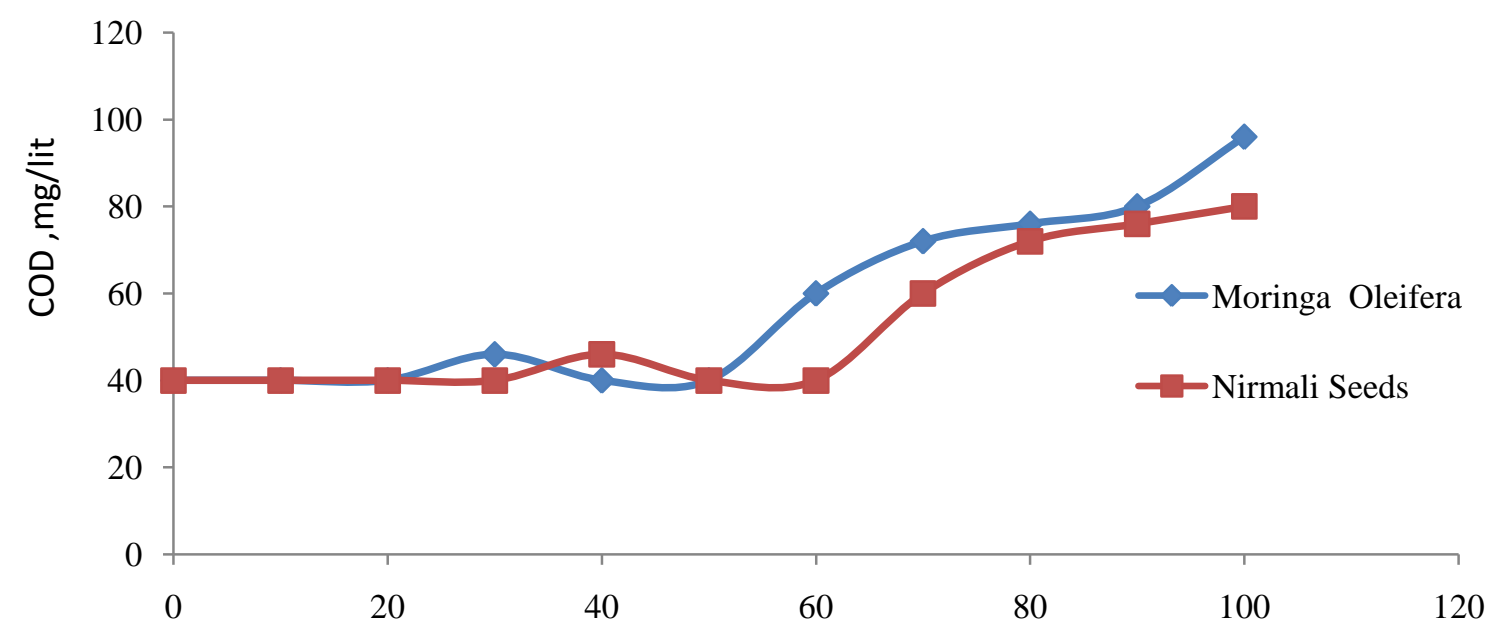

Seed Extract dose $\mathrm{mg} / \mathrm{lit}$

Fig. 5 Variation in COD of water sample with dose of seed extract 


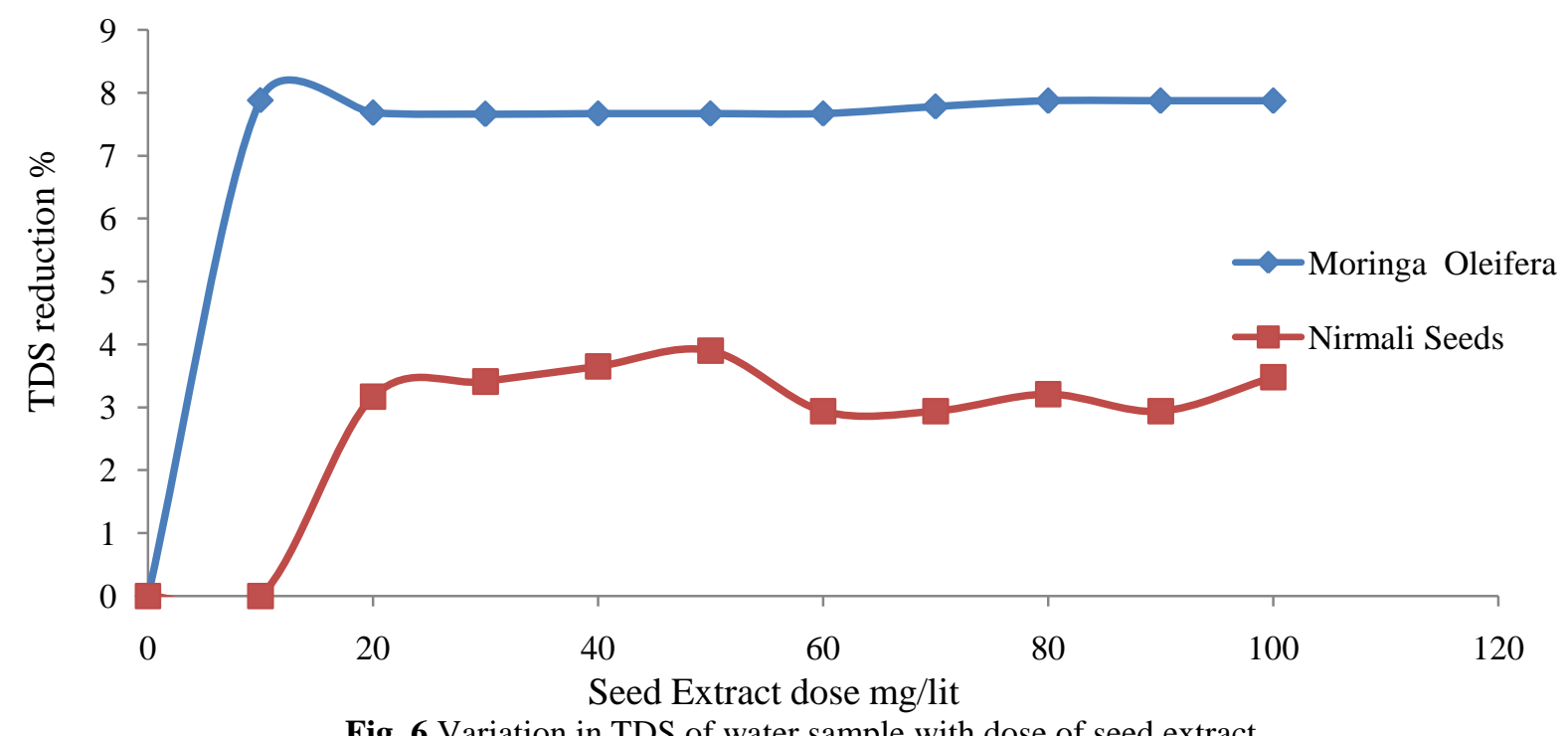

Fig. 6 Variation in TDS of water sample with dose of seed extract

Fig.5 shows that COD of the water sample increases with added dose for both Moringa Oleifera and Nirmali seed extract, as organic matter increases in direct proportion with the added dose of coagulant. Fig.6 shows that TDS reduces with added dose of Moringa Oleifera as well as Nirmali seed extarctas upto optimum coagulant dose. TDS reduction is due to reduction in hardness causing dissolved solids.

\section{CONCLUSION}

After studying the effectiveness of Moringa Oleifera and Nirmali seeds for turbidity and hardness removal for surface water, following conclusions are drawn.

1. Turbidity removal of 66 to $87.5 \%$ was observed with Moringa Oleifera seed extract for river water with optimum dose of $50 \mathrm{mg} / 1$.

2. Turbidity removal of 50 to $91 \%$ was observed with Nirmali seed extract with optimum dose of $50 \mathrm{mg} / \mathrm{l}$.

3. For hardness removal Moringa Oleifera is more effective (7.7 to $47 \%$ removal) with optimum dose of $40 \mathrm{mg} / \mathrm{l}$, as compared to Nirmali seeds (9.8 to $28.6 \%$ removal).

4. Both the coagulants are effective for turbidity removal of surface water, but for the hardness removal Moringa Oleifera is more effective than Nirmali seeds.

5. Both the coagulants can reduce the turbidity of surface water up to 2 to 3 NTU and hardness upto 100-120 mg/lit.

6. Organic matter increases with added dose of natural coagulants.

\section{REFERENCES}

[1] APHA (2005),Standard methods for the Examination of Water and Waste Water.

[2] Bhole A.G. and Shrivastava D.R.(1983), Relative evaluation of a few natural Coagulants, Journal of Indian water works association, 15,270-275.
[3] Garg Santosh kumar (1999), Water supply Engineering, Khanna publishers, and 11,759.

[4] Muyibi A. Suleyman, and Evison Lilian M. (1994), Moringa oleifera seeds for softening hard water, water research, 29(4), 1099-1105.

[5] Muyibi A. Suleyman, and Evison Lilian M. (1995), Optimizing physical parameters Affecting coagulation of turbid water with Moringa oleifera seeds. Water research 29(12), 2689-2695.

[6] Okuda Tetsuji, Baes Aloysius U., Nishijima Wataru, and Okuda Mitsumasa (2001), Coagulation mechanism of salt solution-extracted active component in Moringa oleifera seeds, Water research, 35(3), 830-834.

[7] Raghuwanshi Promodkumar, Mandloi Monik,Sharma Arvind J.,Malviya Hanumat S., and Chaudhari Sanjeev (2002), Improving filtrate quality using agro based materials as coagulant aid. Water quality research journal, Canada, 37(4), 745-756.

[8] Sani M.A. (1990), The use of Zogale seeds for water treatment, B.Engg., Final year Project, Bayero University, Kango, Nigeria.

[9] Varekar V.B. (2009), Water softening by seed extracts, M.Tech. dissertation, Department of civil Engineering, Walchand college of Engineering, Sangli. 